of the cervical canal during the latter weeks of pregnancy he says that the majority of our patients are multiparæ, and that in the great majority of such cases, contrary to the opinion sometimes advanced, there is dilatation of the entire canal, including the internal os. "In nearly every case one or two fingers may be passed through the internal os to the presenting part without the slightest difficulty," and " if the ante-partum examination of pregnant women proves anything at all, it proves that in multiparæ dilatation of the cervix is no evidence of labour." Still, though the internal os is open it forms a ringa tense and resisting ring. Dilatation of the cervical canal, including the internal os, even to the point of admitting two or more fingers may mean nothing; but dilatation of the internal os in such a way that what is left of the canal of the cervix begins to form part of the uterine cavity means labour. Only those contractions which are accompanied by this kind of dilatation deserve the name of "labcur pains." At first the change can only be noted during the pains, but as labour advances it becomes appreciable during the intervals.

To sum up, he says that the statement made in many text-books that the cervix maintains its entire length during pregnancy is incorrect. The statement sometimes made that the canal of the cervix remains closed until the beginning of labour is also incorrect. Usually in multiparæ, and occasionally in primiparæ, the canal including the internal os is dilated to the extent of admitting one or two fingers two or three weeks before labour begins. Dilatation of the external or internal os or of the cervical canal is not per se an indication of beginning labour. Dilatation of the clinical internal os, or ring of Müller, in such a manner that it begins to form part of the uterine cavity, is at once the anatomical commencement and the diagnostic sign of true labour. Dilatation at this point is the final result of uterine distention and consequent cervical eversion. Dilatation at this point, owing to the greater resistance offered, by its effect upon the cervical ganglion, and the consequent reflex awakening of effectual uterine contractions, is the physiological cause of labour.

$$
1 \text { New York Med. Rec., Aug. } 23 .
$$

\section{BANTI'S 'DISEASE.}

IT is now twenty years since Professor Banti of Florence described the condition which has since been known as Banti's disease. Under the generic name of splenic anæmia doubtless a considerable number of separate diseases are included. Although many writers use the terms "Banti's disease," "splenic anæmia," "splenic cachexia," "splenic pseudo-leukæmia," "lymphadenoma splenica," and "splenomegalia primitiva," as synonymous, Dr. James Barr ${ }^{1}$ holds, and probably very correctly holds, that under these various designations many varieties of disease have been included, the conditions common to all of which have been a large spleen with more or less wellmarked anæmia. According to Banti's description of the malady to which his name has been attached, the clinical features were anæmia with enlargement of the spleen and secondary cirrhosis of the liver with ascites ; frequent hæmorrhages, such as epistaxis, bleeding of the gums, hæmatemesis, and melæna. Pathologically he recognised fundamental and strik- ing changes in the sympathetic nervous system, consisting of lymphoid infiltration of the stroma of the ganglia, fatty and pigment degeneration of the ganglion cells, and a degeneration of the nerve fibres springing from the ganglia; these changes being found not only in the semilunar ganglia and solar plexus of the abdomen, but also in the ganglia of the neck. The changes in the chyle and hæmopoietic organs (as the stomach, bowels, spleen, and liver), had a great influence on nutrition, so that the cause of the anæmia which was so striking a symptom in the cases was very apparent. He regarded the tumefaction or engorgement of the spleen and liver as the primary condition, and the fibrosis of these organs which followea' as a secondary consequence. Dr. Barr relates three cases of this disorder, and in summing up says that his view of Banti's disease is that it is probably due to a vaso-motor paresis of the splanchnic area, either in whole or in part, and that this paresis arises from disease of the visceral' sympathetic ganglia. As a consequence of this there is great engorgement of the abdominal viscera, especially of the spleen and liver, increased hæmolysis, with consequent oligochromæmia and oligocythrmia. The increased blood supply to those organs eventually leads to fibrosis and lessened function. The paresis also leads to retention of blood in the portal area with lessened supply to the rest of the body and general impairment of nutrition. The peritoneal effusion would seem to be due: to vascularity rather than to portal obstruction.

$$
1 \text { Lancet, Aug. } 23 .
$$

\section{METHYLATED SPIRIT DRINKING.}

THE methylated spirit of commerce is a compound. containing 10 per cent. of wood naphtha, 2 per cent. of mineral oil, and 64 per cent. of absolute alcohol. It contains twice as much alcohol as the finest whisky and can be retailed at a considerable profit for $5 \mathrm{~d}$. per pint. There is no restriction as to its sale, provided that its composition conforms to the above formula, and that the retailer obtains a license which costs but 10s. a year, although somewhat recently the Inland Revenue Authorities have forbidden the sale. of methylated spirits to the public between the hours of 10 o'clock on Saturday night and 8 o'clock on Monday morning. Dr. J. C. McWalter ${ }^{1}$ clearly? shows that illimitable possibilities for evil must. result from this unresiricted sale of methylated. spirit. There is no doubt but that large numbers seek in this agent a cheap intoxicant. Habitual drinkers have not been slow to discover that the oily constituents may at least in part be removed by dilution of the spirit with water and subsequently skimming. Both the wood naphtha and the inineral oil possess important toxic properties. We have in fact in the methylated spirit of commerce a fluid. compounded of three powerful intoxicants, capable of producing intensely greater effects than the most virulent form of raw whisky. Dr. McWalter: thinks the addition of naphthaline may prove an effectual deterrent. He also shows that the drinking of ether in the North of Ireland was stopped by the simple expedient of putting it on the schedule of poisons; and suggests that a like step taken in regard to methylated spirit would ensure its sale being confined to chemists and secure the 
labelling of it as "poison." Certainly measures should be speedily found which, while providing for the legitimate use of methylated spirit in the arts and as a convenient domestic fuel should prevent its use as "a beverage."

1 The Journal of State-Medicine, August 1902.

THE MISUSE OF GLASSES.

Is an address delivered at Chicago Dr. F. C. Hotz, ${ }^{1}$ draws attention to the mischief done by prescribing glasses for the relief of asthenopia in cases in which a more careful search might have revealed some pathological condition of the conjunctiva quite sufficient to account for the difficulty complained of. The point which he seems to make is this, that there are a large number of people going about in perfect comfort who, for all that, do not possess a degree of vision which is perfectly normal according to the tests of the ophthalmic surgeon. Their ametropia is perfectly capable of correction by appropriate glasses, but it does them no harm and at the most is less irksome than the wearing of spectacles. Should such a person, however, happen to be attacked with a conjunctivitis affecting the retrotarsal fold, where it is not easily seen, or with a slight degree of blepharitis, a certain difficulty of vision is at once produced, and if the physician, on discovering the refractional abnormality, should prescribe glasses - which he is very apt to do, either in consequence of not discovering the inflammatory complication or of wrongly regarding it as a consequence of the eye strain-he may not only fail to cure the complaint, but may do his patient considerable injury. As he says : "If such persons have faithfully used their glasses for a year or two without benefit, and if then they are relieved of their complaints in a week or two by the proper treatment of the blepharitis, and thereafter continue their work in perfect comfort, though they do not use glasses, we are forced to the conclusion that the glasses were unnecessary." The moral seems then to be the very old one, that we should not decide upon treatment without a full examination, especially of the retrotarsal fold and the margins of the lids, and that we should remember that moderate errors of refraction may be positively demonstrable, and yet not be the cause of the visual difficulty complained of.

1 New York Medical News, Aug. 16.

\section{RUPTURE OF THE PERINEUM.}

Is a lecture delivered at the London Polytechnic, Dr. Gow ${ }^{1}$ made some remarks on rupture of the perineum which may convey some comfort to those who have had the misfortune to preside over the occurrence of this by no means unfrequent accident. There is a common idea, that the occurrence of rupture of the perineum is a slur on the skill of the practitioner, and the indirect result of that belief is that in many cases where the perineum is torn it is not sewn up again, so as to avoid exposing the supposed fault. But I think, hes says, there has not yet been invented any device which will prevent the perineum rupturing in many cases. "You will meet with people who will tell you-and I have met with many-that in the cases they attend the perineum never ruptures. That on the face of it is really absurd." The perineum ruptures in a certain proportion of cases of primiparæ. That it does not often rupture in multipare is due to the fact that the majority of these people do not possess a perineum, and therefore rupture does not occur for the best of. reasons. When people say they do this or that, and the consequence is that their patients do not have ruptured perineums, it seems to imply that if there is a rupture there must be some fault. As a matter of fact, whether the perineum ruptures or not depends infinitely more on the perineum than on the medical attendant. "Bearing in mind, then, that rupture of the perineum is frequently inevitable in normal delivery, there can be nothing to be ashamed of from the fact that it occurs. And, if one does not boast of one's ability to prevent it, there is no reason why one should not sew it up when it does occur." That is the great point.

1 The Clin. Jour., Aug. 27.

\section{Progress in Fevers.}

\section{(Continued from page 381.)}

Scarlet Fever.-The diagnosis of scarlet fever is dealt with by $J$. Marshall Day ${ }^{10}$. The classical symptoms of vomiting, sore throat, rash, elevation of temperature, and increased pulse rate are enumerated. Special stress is laid on the increase of pulse rate, out of proportion to the temperature, which in mild cases may be slight and transient. The presence or absence of complaint of sore throat or dysphagia is delusive ; dysphagia may be present in a simple relaxed throat and absent in a severe scarlatinal throat. The fauces should in all cases be carefully inspected. The red punctiform appearance especially on the hard palate is very characteristic. A peculiar dull yellowish white appearance of the hard palate may sometimes be observed in mild cases on the second day. In mild cases the fine punctiform rash should be sought for on the fauces and the soft parts of the skin, the flexures of the limbs, and the sides of the chest and abdomen. It can be detected also on the sides of the fingers and the backs of the hands and feet.
A browning of the skin may also be observed in the elbow flexures and at Poupart's ligament, less frequently behind the knees. The "strawberry" tongue, stripped of epithelium and showing prominent fungiform papillæ, must be distinguished from the lightly furred tongue with projecting filiform papillæ observable on the third or fourth day of a gastric catarrh. The milder the case the more delayed the desquamation, which, in very mild cases, may not begin for three weeks and then takes the form of polishing of the finger-tips, roughness at the joint flexures, and later stripping of the feet. In Rötheln vomiting, very common in scarlet fever, is rare, the pulse is less frequent, the fever is slight and commonly subsides in 24 hours, the tongue does not peel, there is no browning at the joint flexures, and glandular enlargement is common. Care is sometimes needed to distinguish scarlet fever from septicæmia or from meningitis. The sudden onset, purplish slightly swelled throat, patchy dark brown or petechial rash, 